\title{
Simulation of MOSFET Based Inverter for Induction Heating In MATLAB
}

\author{
A. Hakim A. Razzaque Shaikh ${ }^{1}$, Shravan Kumar Akireddy ${ }^{2}$ \\ ${ }^{1}$ Fabtech College of Engineering and Research, Solapur University / Solapur, Maharashtra, India \\ ${ }^{2}$ Professor, Fabtech College of Engineering and Research, Solapur University / Solapur, Maharashtra, India
}

\begin{abstract}
This paper illustrate use of series resonant half bridge inverter for induction heating appliances. For Induction Heating high frequency inverter circuit is used, which can deliver output at different frequencies by Metal Oxide Semi Conductor Field Effect Transistor (MOSFET).The series resonant inverter is implemented to provide Zero Current Switching (ZCS) for all switches at turn off condition and Zero Voltage Switching at diode turn on. To achieve the desired high frequency with reduced switching losses resonant inverter is used. MATLAB / SIMULINK is used for simulating the power electronic converter circuit used for Induction Heating appliances. By changing the frequency of inverter, variable output power is obtained.
\end{abstract}

Keywords: Simulation, MOSFET, Zero Voltage Switching (ZVS), Zero Current Switching (ZCS), Half bridge resonant inverter.

\section{Introduction}

Induction heating can be utilized for various application like Scan hardening, strip heating, counter hardening, single-shot hardening, melting, brazing, bonding, forging, fitting and heat treatment etc [1]. The heating of workpiece is obtained by employing electromagnetic induction theory and the distribution of power density inside the heated workpiece is acquired effectively by the selection of power supply frequency and the appropriate design of induction coil [2]. In previous days vacuum tube oscillator based high frequency power supply were used for induction heating application above $100 \mathrm{KHz}$. This led to defects such as huge volume, short life time, and low efficiency and preheating. With the development in the field of high power semiconductor device technology, various switching devices like static induction transistor (SIT), insulated gate bipolar transistor (IGBT), and metal oxide semiconductor field effect transistor (MOSFET) high frequency power supply can be achieved with great success [3]. IGBT is widely used in generators as it has low on resistance and also it needs very little power to drive its gate. IGBT can be used for frequency up to $60 \mathrm{KHz}$, but not suitable for above $60 \mathrm{KHz}$ frequency.SIT can be used but it has drawback like high conduction loss, complicated fabrication process, high cost and price which restrict its used. Whereas MOSFET has advantage like high switching speed, can be connected in parallel which makes it useful for obtaining high range frequencies from $60 \mathrm{KHz}$ to $500 \mathrm{KHz}$.

\section{Induction Heating Principle}

A source of high frequency electricity is used to drive a large alternating current through a coil. This coil is known as the work coil. The passage of current through this coil generates a very intense and rapidly changing magnetic field in the space within the work coil. The workpiece to be heated is placed within this intense alternating magnetic field. The alternating magnetic field induces a current flow in the conductive workpiece. The arrangement of the work coil and the workpiece can be thought of as an electrical transformer. The work coil is like the primary where electrical energy is fed in, and the workpiece is like a single turn secondary that is short-circuited. This causes tremendous currents to flow through the workpiece. These are known as eddy currents.

In addition to this, the high frequency used in induction heating applications gives rise to a phenomenon called skin effect. This skin effect forces the alternating current to flow in a thin layer towards the surface of the workpiece. The skin effect increases the effective resistance of the metal to the passage of the large current. Therefore it greatly increases the heating effect caused by the current induced in the workpiece.

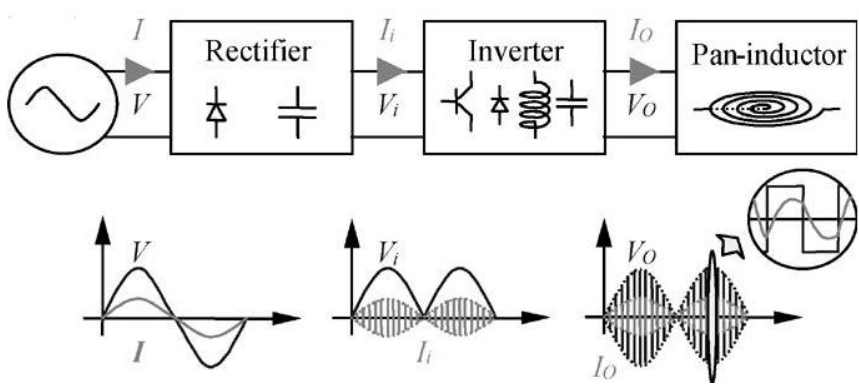

Figure 1: Typical arrangement of induction heating system

\section{Series Resonant Inverter}

To energize the induction coil to generate high-frequency magnetic induction between the coil and the workpiece the Class-D inverter is used; this generates high-frequency eddy currents and heat in the workpiece area. Class-D inverters take the energy from the mains voltage. By using a Class-D inverter the DC voltage is converted again into a highfrequency $\mathrm{AC}$ voltage. Then the inverter supplies the highfrequency current to the induction coil. Series resonant converters, operated above the resonant frequency, show many advantages: inherent short circuit protection, zerovoltage commutations, limited harmonics in the resonant current, maximum power transfer at minimum switching frequency, transformer leakage inductance included in the resonant link, etc. Their main limitation is that for reduced

\section{Volume 4 Issue 11, November 2015}




\section{International Journal of Science and Research (IJSR) \\ ISSN (Online): 2319-7064 \\ Index Copernicus Value (2013): 6.14 | Impact Factor (2014): 5.611}

load current, they lose the soft commutation advantage and the output voltage cannot be controlled anymore. Moreover, converter transfer function strongly depends on the load value.

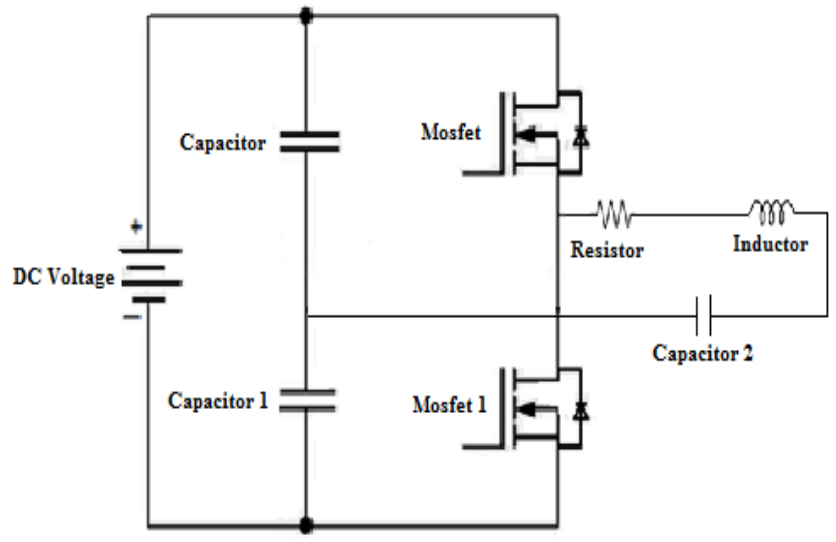

Figure 2: MOSFET based half bridge series resonant circuit

To obtain the desired output power control without varying the input voltage, there are generally two possible switching schemes for this converter, i.e. load commutation and forced commutation. In this paper, the load commutation is applied. At the upper point of the switching frequency range, usually about $70 \mathrm{kHz}$ maximum power was obtained.

\section{Operating Modes of Inverter}

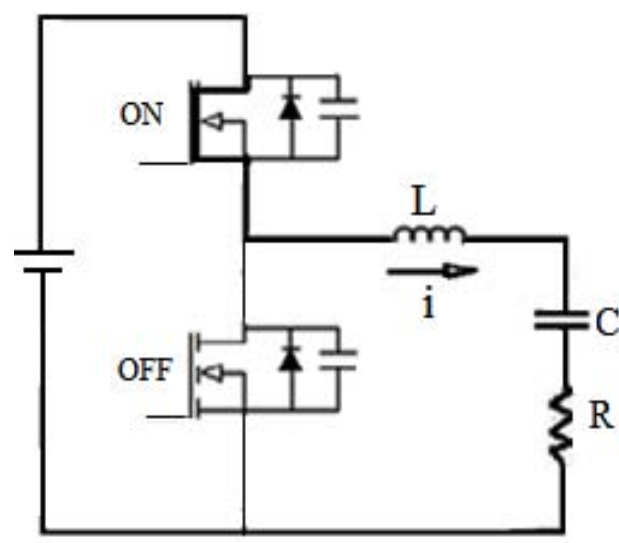

Mode-I

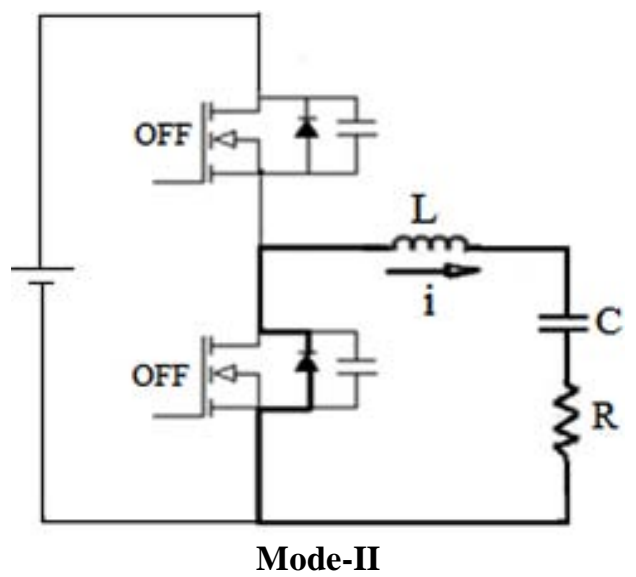

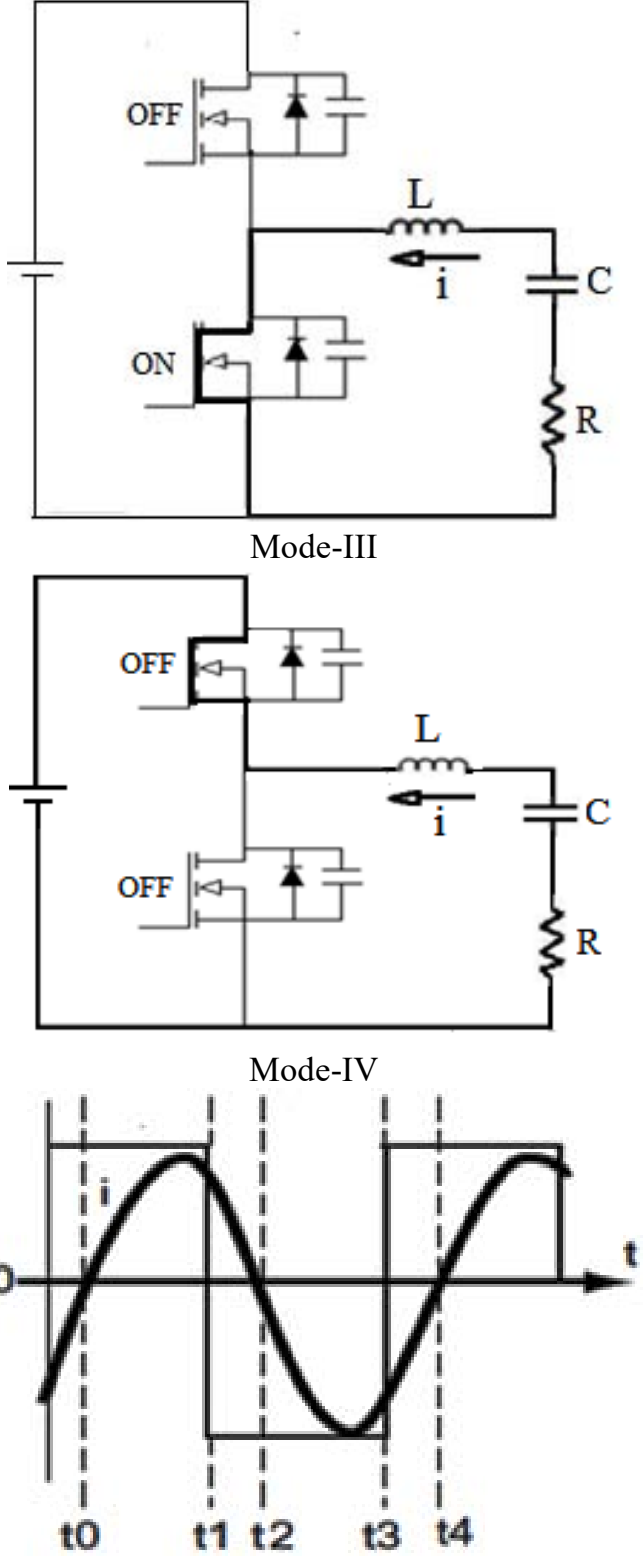

Figure 3: Waveform for inverter

\section{Modes of Operation}

Mode I: $t_{0}-t_{1}$

The direction of resonant current flowing through $S_{1}$ in an inverse direction changes at the point of $\mathrm{t}=\mathrm{t} 0$. In this mode power is drawn through $\mathrm{S}_{1}$, and stored in the resonant circuit.

Mode II: $t_{1}-t_{2}$

When $S_{1}$ is turned off at the point ' $t=t_{1}$, the resonant current flowing through $\mathrm{S}_{1}$ begins free-wheeling through the $\mathrm{D}_{2}$ diode,. In this process, as the $\mathrm{S}_{1}$ switch is turned off a small amount of switching turn-off loss occurs while retaining some values in voltage and current. For the following mode, $S_{2}$ is turned on when $t_{1}<t<t_{2}$. As the $S_{2}$ switch remains at zero voltage/current, no switching loss takes place at turn-on. After turning off $\mathrm{S}_{1}$, the resonant current, before freewheeling to $\mathrm{D}_{2}$, passes for a short period through the snubber $\mathrm{C}_{1}$.

Mode III: $\mathrm{t}_{2}-\mathrm{t}_{3}$ 


\section{International Journal of Science and Research (IJSR) \\ ISSN (Online): 2319-7064}

Index Copernicus Value (2013): 6.14 | Impact Factor (2014): 5.611

At $\mathrm{t}=\mathrm{t}_{2}$, as $\mathrm{S}_{2}$ is already turned on the current freely resonates and flows in an inverse direction through it. Here, the resonant capacitor, $\mathrm{Cr}$, serves as a source of voltage.

Mode IV: $\mathrm{t}_{3}-\mathrm{t}_{4}$

At $t=t_{3} \quad S_{2}$ is turned off. The resonant current flowing through $\mathrm{S}_{2}$ starts freewheeling through the $\mathrm{D}_{1}$ diode. In this process, a small amount of switching loss occurs at turnoff. When the $S_{1}$ switch is turned on at a certain point $\left(t_{3}<t<t_{4}\right)$ there is no switching loss as the $S_{1}$ switch remains at zero voltage/current. And the reverse recovery of $\mathrm{D}_{2}$ does not have to be fast. In this mode, the energy of the resonant circuit is converted to $\mathrm{Vdc}$ passing $\mathrm{D}_{1}$. The operating mode after $\mathrm{t}>\mathrm{t}_{4}$ cycles is repeated from mode I to mode IV again in loop as described above. Also in this process, the resonant current, before freewheeling through $D_{1}$, passes through the snubber $C_{2}$ for a short period of time. $[6][7]$

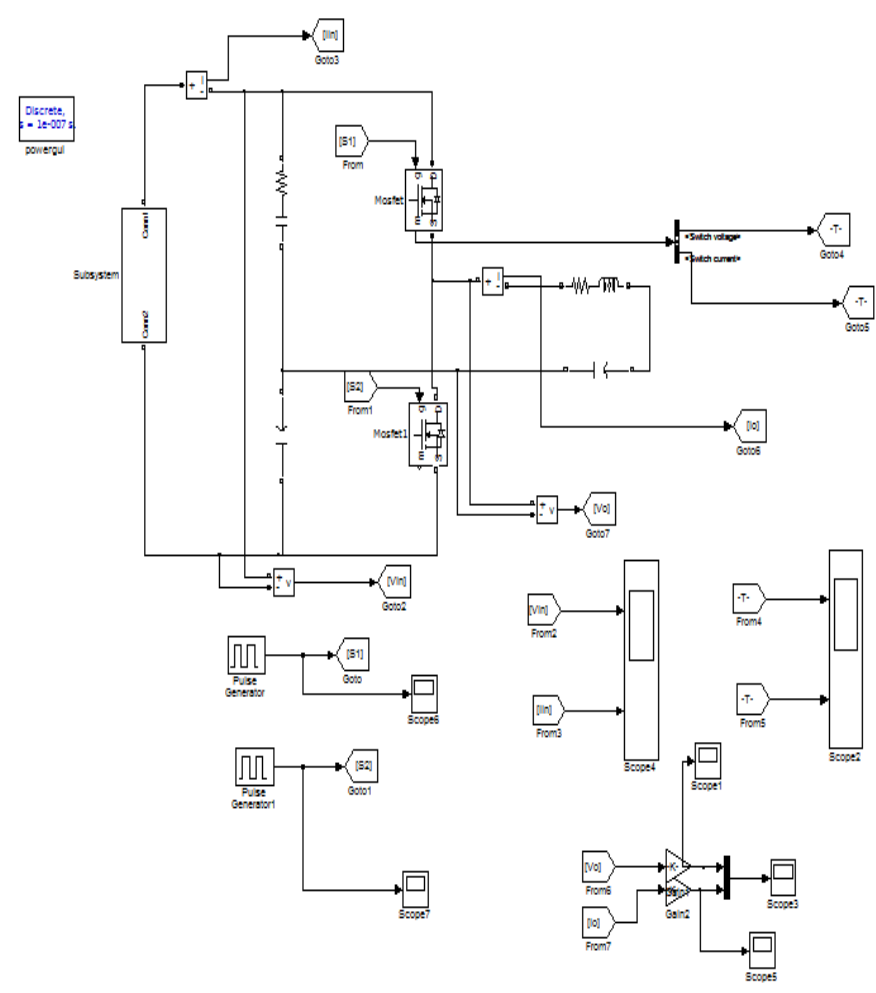

Figure 4: Simulation model

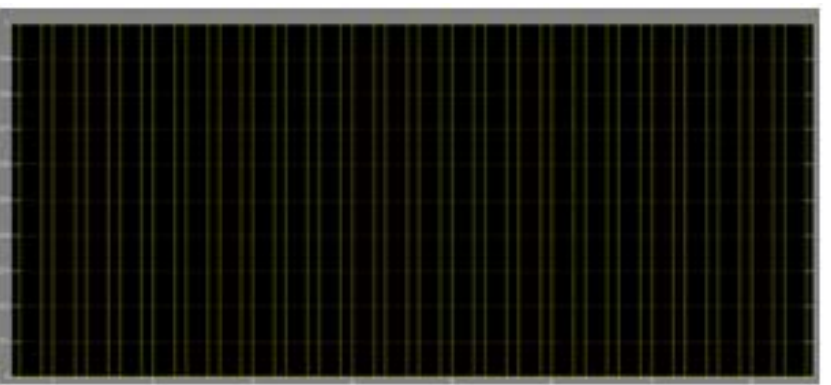

Figure 5: Gating pulse of Mosfet and Mosfet 1

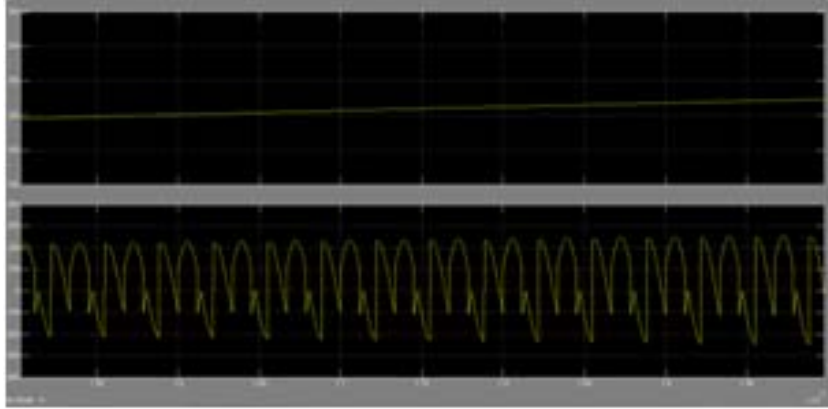

Figure 6: Input voltage and input current waveform

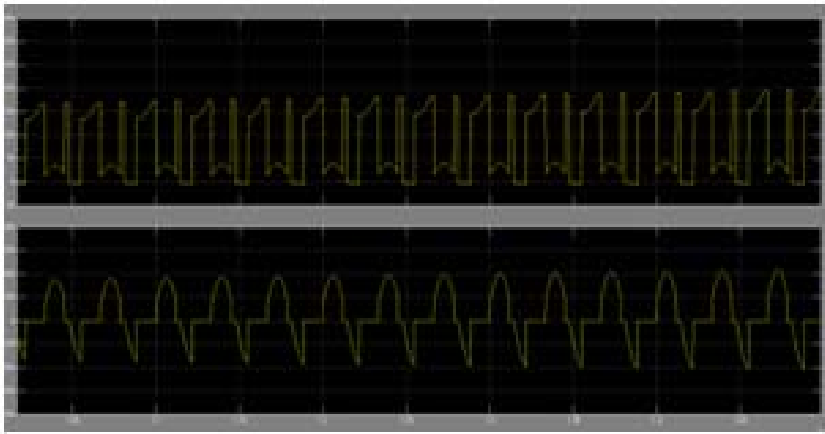

Figure 7: Switching voltage and current waveform

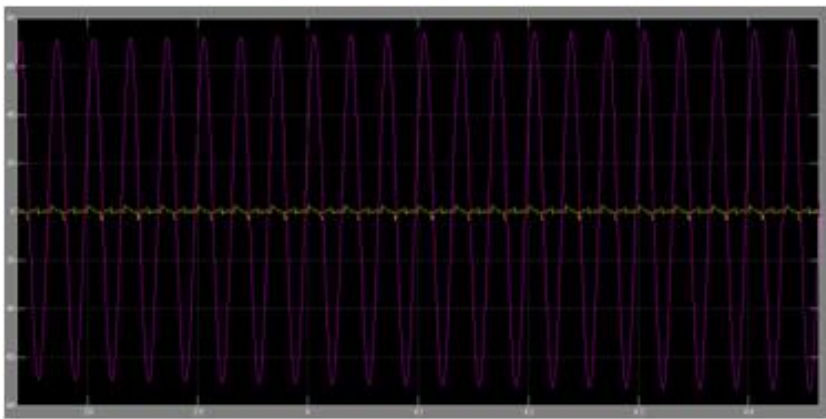

Figure 8: Output voltage and current waveform

\section{Conclusion}

This paper illustrates a high frequency resonant inverter topology which utilizes the pulse width modulation technique to control the series resonant inverter for induction heating equipments. The results of the performance of the proposed system are elaborated using Matlab/Simulink environment. The series-resonant inverter is implemented to provide Zero Current Switching (ZCS) for all the switches at turn off conditions and Zero Voltage Switching (ZVS) at diode turn on. Simulation results reveal that the proposed resonant modular inverter is capable of adjusting the output sinusoidal current with the resonant frequency at different conditions. The main advantages of this inverter system are Wide power regulation, reduction in size and weight. Due to all above advantages such inverters are used for heat treatment like strip heating, contour hardening and shot hardening in industry.

\section{References}

[1] N.S. Baytndtr, 0 Kukrer and M. Yakup, "DSP-based PLL-controlled $50-100 \mathrm{kHz} 20 \mathrm{~kW}$ high-frequency inducton heating system for surface hardening and 
welding applications," lEE Proc-Electr. Power App!., Vo!'150, No. 3, May 2003.

[2] Arbab Waleed Ahmad. College of E\&ME NUST,Fanrukh Kamran CARE (Pvt) Ltd. "TANDEMH Bridge" A New Approach towards Low Switching Loss at High Switching Frequencies, International Conference on Emerging Technologies IEEE 2005.

[3] S. Zinn, S. L. Sem "Elements of Induction Heating: Design Control and Applications" ASM International 25-73 pages.

[4] Prof. Ruchit R. Soi , Prof. Hirenkumar D. Patel, Mr. N. D. Patel, Mahendra Rathod, "Hardware Implementation of MOSFET Based High Frequency Inverter for Induction Heating" ISSN: 0975 - 6736| NOV 12 TO OCT 13 | VOLUME - 02, ISSUE - 02

[5] H. W. Koertzent,1. D. Van Wyk and 1. A. Ferreira, "Design of the Half bridge, series resonant converter for induction cooking," The Proceeding of the $26^{\text {th }}$ IEEE Power Electronics Specialists Conference, 1995, pp.729735.

[6] Induction heating system topology review, Discrete Application, Power Device Division, Fairchild Semiconductor, AN9012, July, 2000.

[7] N. Sanajit and A.Jangwanitler "A series resonant inverter half bridge inverter for Induction iron appliancas" 978-1-4577-0001-9/11/\$26.00 C2011 IEEE.

[8] Mokhtar Kamli, Member, IEEE, Shigehiro Yamamoto, and Minoru Abe"A 50-150 kHz Half-Bridge Inverter Induction Heating Applications" IEEE TRANSACTIONS ON INDUSTRIAL ELECTRONICS, VOL. 43, NO.1 PP163-173, FEBRUARY 1996.

[9] Muhammad H. Rashid, "Power electronics circuits, devices, and application," Third Edition, September 2003, Pearson/Prentice Hall, New Jersey United states.

\section{Author Profile}

Shaikh A. Hakim A. Razzaque completed B.E from AISSMS College of engineering Pune in 2009 and pursuing M.E in Electrical Engineering from Fabtech Technical Campus college of Engineering and Research, Sangola, Solapur.

Akireddy Shravan Kumar completed M. Tech from Walchand College of engineering Sangli in 2009 and Working as Assistant Professor in Electrical Engineering Department at Fabtech Technical Campus College of Engineering and Research, Sangola, Solapur since 27th July 2011. 